\title{
SIMULATION OF AN INDUSTRIAL ADIABATIC MULTI-PACKED BED REACTOR FOR METHANOL SYNTHESIS WITH ACTIVITY FUNCTION
}

\author{
Raíza Del C. Sánchez R. \\ Universidad de Oriente, \\ Barcelona, Anzoátegui,Venezuela
}

\begin{abstract}
In this study, a computational model that simulates an adiabatic packed five-bed industrial reactor with inter-stage cooling for Methanol synthesis was developed. The simulator contents a steady-state, onedimensional and pseudo-homogeneous mathematical model, which includes the kinetic model for Methanol production from $\mathrm{CO}_{2}$ presented by Bos et al. (1989), and the kinetic model for methanol, production from CO published by Skrzypek et al. (1995). A theoretical effectiveness factor based on Thiele module was used and an activity function time-dependent was built by fixing operational data to activity models presented by Froment, G. and Bischoff, K. (1979). The simulation results were validated with operational data, finding that this computational model represents the behavior of the industrial reactor for methanol synthesis along the operational time evaluated with an absolute deviation of less than $8 \%$ and an average relative deviation of $0.26 \%$. The simulation model developed could be used to predict the methanol production in this type of industrial reactors.
\end{abstract}

Keywords: quench, pseudo-homogeneous, operational data, Thiele module, catalytic, synthesis gas, computational model.

\section{INTRODUCTION}

Methanol is a basic chemical in the petrochemical industry with a growing worldwide demand for being the basis for the production of chemicals such as formaldehyde, MTBE, acetic acid, solvents, and ethyl amines, among others.

Methanol is mainly produced from natural gas, and the process used involves the following basic units: natural gas reformer, compression, synthesis, distillation, steam recovery system and heat recovery system. Being the heart of the process, the catalytic reactor that converts the pressurized synthesis gas ( $\mathrm{CO}, \mathrm{CO} 2$, and $\mathrm{H} 2$, mainly) into methanol, through the hydrogenation reactions of carbon monoxide and carbon dioxide in solid catalysts formed mainly by $\mathrm{Cu}$ and mixtures of oxides such as $\mathrm{ZnO}-\mathrm{Al} 2 \mathrm{O} 3$ or $\mathrm{ZnO}-\mathrm{Cr} 2 \mathrm{O} 3$ at low pressure.

\author{
Fanny J. Yaguaramay L. \\ Universidad de Oriente, \\ Barcelona, Anzoátegui,Venezuela
}

The optimization and control of the methanol synthesis process require a fast, efficient and conscious means of reliable economic technical analysis, which can only be obtained through a simulation.

The simulation of a process allows to predict effects of changing conditions and capacities, performing mass and energy balances quickly, allows manipulating the time scale to obtain process information at speeds much faster or slower than those that characterize the actual process. In addition, these facilities are carried out without the economic and fiscal risks inherent in the actual process management.

The simulation of a process allows to predict effects of changing conditions and capacities, performing mass and energy balances quickly, allows manipulating the time scale to obtain process information at speeds much faster or slower than those that characterize the actual process. Most of these simulators were developed for vapor-liquid processes of the petrochemical industry and are not suitable for processes involving solids or complex substances such as coal.

To simulate a process requires a mathematical model that represents it. Mathematical models for designing packed catalytic reactors are established from their continuity equations, which are common differential equations or algebraic expressions.

The catalytic reactor mathematical models designed contain the reactions rate, effectiveness factors, and mass and heat transfer coefficients, among others. Kinetic equations are some of the important resources to guarantee the success of the model.

In the present study, the simulation of the Mitsubishi industrial catalytic reactor for methanol synthesis is proposed, using operational data presented by Lárez, F. (1998) to develop a tool that allows the evaluation, optimization, and design of industrial methanol synthesis reactors. 


\section{International Journal of Engineering Applied Sciences and Technology, 2019 Vol. 4, Issue 7, ISSN No. 2455-2143, Pages 35-41 \\ Published Online November 2019 in IJEAST (http://www.ijeast.com)}

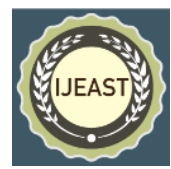

\section{MATERIALS AND METHODS}

\section{A. Reactor simulation}

The methanol synthesis reactor of the Mitsubishi Gas Chemical Co is an adiabatic multi-packed bed "Quench" type reactor with cylindrical form, top, and bottom semi-spherical vertically installed. Made from stainless steel $0.5 \%$ de molybdenum in the inside and cover with a housing made by carbon steel in which inside there is an isolator, which give the adiabatic feature.

The reactor is formed by five catalytic beds, supported between two stainless steel grilles. The beds are equidistant from each other with a separation of $1.500 \mathrm{~mm}$. The size or depth thereof varies with the depth of the reactor, the more distant the bed is from the reactor feed the deeper it will be. The dimensions are $1.140 ; 1.370 ; 1.930 ; 2.760$ and $3.950 \mathrm{~mm}$, from the first to the fifth bed respectively, located from top to bottom. The sizing of the beds is intended to compensate the main reaction rate decrease by increasing the concentration of methanol in the gas stream, increasing progressively the contact surface between the catalyst and the gas.

In each bed, there is a point of fast cooling gas injection or "Quench" gas, destined to control the temperature of the synthesis gas entering each bed and therefore the temperature of the reactor. That is necessary because the methanol synthesis reaction is exothermic, of limited equilibrium and is carried out with a volume decreasing; therefore, it is favored at low temperatures and high pressures. The reactor has gas distributors in each bed so that the contact with the catalyst is homogeneous and the catalyst is not used unevenly, does not suffer drag, nor can channels be produced. The reactor operates at pressure of $100 \mathrm{Kgf} / \mathrm{cm} 3 \mathrm{G}$ and temperature of 230 ${ }^{\circ} \mathrm{C}$ at the inlet of the unit and $260{ }^{\circ} \mathrm{C}$ at the outlet. The unit height, not including the top and bottom, is $18,159 \mathrm{~mm}$. A diagram of the Reactor is shown in Figure 1.

For the simulation of the industrial methanol synthesis reactor, a one-dimensional and pseudo homogeneous model was developed. A program which includes the third-order Runge Kutta method to resolve the mass and energy differential equations was written in Visual Basic language.

The following properties belong to $\mathrm{Cu}$ catalyst pill with cylindrical form were used: Diameter $5.4 \mathrm{~mm}$, length $5.2 \mathrm{~mm}$ and density $1.2-1.3 \mathrm{~kg} / \mathrm{l}$.

The simulation was carried out for an industrial methanol plant operational data collected by Lárez, F. (1998). A typical feed synthesis gas composition is shown in Table 1. Operational data from the plant report are the media of the variables measured in two hours and is showed in Table 2.

\section{B. Reactions and kinetic model}

In the methanol production process, both $\mathrm{CO}$ and $\mathrm{CO} 2$ react with $\mathrm{H} 2$ to convert into methanol. These reactions together with the water shift reaction are:

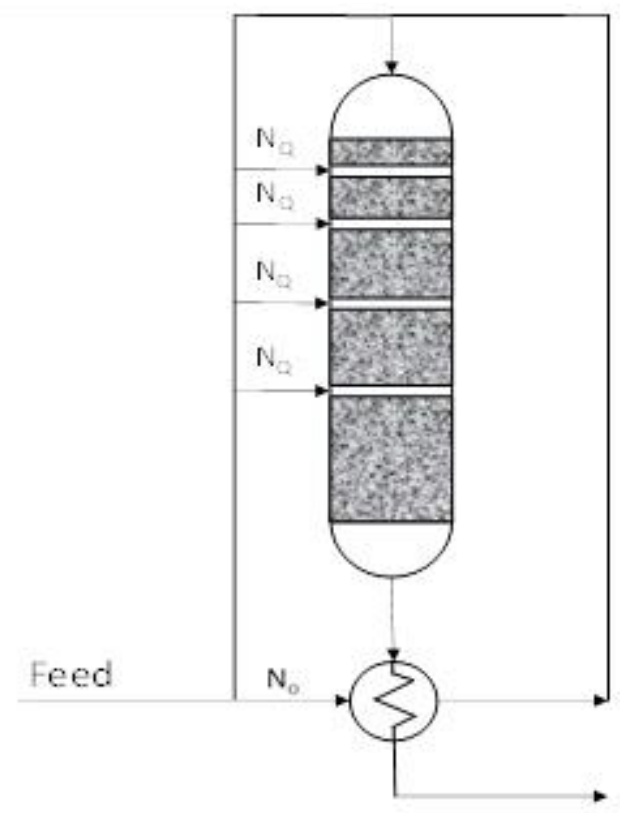

Figure 1. Adiabatic fixed bed reactor with indirect inter-step cooling scheme.

$\mathrm{CO}+2 \mathrm{H}_{2} \leftrightarrow \mathrm{CH}_{\mathrm{a}} \mathrm{OH}$

$\mathrm{CO}_{2}+3 \mathrm{H}_{2} \leftrightarrow \mathrm{CH}_{2} \mathrm{OH}+\mathrm{H}_{2} \mathrm{O}$

$\mathrm{CO}_{2}+\mathrm{H}_{2} \leftrightarrow \mathrm{CO}+\mathrm{H}_{2} \mathrm{O}$

As only two reactions of those and independent, for methanol synthesis by $\mathrm{CO}$, a model presented by Bos et al. (1989) was used. They determined this model in a lowpressure system, begun from feed that content $\mathrm{CO}$ and $\mathrm{H} 2$, in a mixed reactor without internals gradients, with pressure variation from 3 to $7 \mathrm{MPa}$ and temperature from 503 to 553 ${ }^{\circ} \mathrm{K}$, using a commercial $\mathrm{Cu} / \mathrm{ZnO} / \alpha \mathrm{Al} 2 \mathrm{O} 3$ catalyst, they showed four models, from which the following was selected:

$r_{C O}=\frac{\left(k r\left(\Phi_{C O} \Phi_{H z}^{2}-\Phi_{M} / K_{e q}\right)\right.}{\left(1+K_{C O} \Phi_{C O}+K_{H z} \Phi_{H z}^{2} \Phi_{C O}\right)}$

The required parameters for the model are:

$$
\begin{aligned}
& \ln K_{e q}=-28,9762+11,815 / T \\
& K_{y}=E X P\left\lfloor-14,7-\left(86 \times 10^{a} / R\right)(1 / T-1 / 523)\right\rfloor \\
& K_{\text {Co }}=E X P\left\lfloor-4,74+\left(143 \times 10^{3} / R\right)(1 / T-1 / 523)\right\rfloor \\
& K_{H 2}=E X P\left\lfloor-9,13-\left(39 \times 10^{a} / R\right)(1 / T-1 / 523)\right\rfloor
\end{aligned}
$$


Table 1- Typical composition of the gas to methanol reactor

\begin{tabular}{|c|c|}
\hline Component & \% mole \\
\hline $\mathrm{CH}_{4}$ & 14.975 \\
\hline $\mathrm{CO}$ & 2.422 \\
\hline $\mathrm{CO}_{2}$ & 1.928 \\
\hline $\mathrm{H}_{2}$ & 80.587 \\
\hline
\end{tabular}

Table 2- Operational data for industrial methanol synthesis reactor

\begin{tabular}{|c|c|c|c|c|c|}
\hline Operation days & 47 & 78 & 137 & 195 & 236 \\
\hline Temperature in, ${ }^{\circ} \mathrm{C}$ & 214.425 & 218.075 & 220.2 & 223.175 & 225.275 \\
\hline Pressure in, atm & 94.4 & 97.8 & 98.925 & 98.475 & 98.8 \\
\hline $\begin{array}{c}\text { First Quench flow, } \\
\mathrm{KNm} 3 / \mathrm{h}\end{array}$ & 108.57 & 97.3 & 75.72 & 82.675 & 74.12 \\
\hline Flow in, kNm3/h & 591.1 & 607.07 & 634.67 & 622.05 & 643.5 \\
\hline $\begin{array}{c}\text { Methanol crude, } \\
\text { ton/day }\end{array}$ & 2145.2 & 2244.5 & 2268.4 & 3228.5 & 2204.5 \\
\hline Operation days & 296 & 397 & 428 & 474 & 518 \\
\hline Temperature in, ${ }^{\circ} \mathrm{C}$ & 225.525 & 229.825 & 230.125 & 230.575 & 232.15 \\
\hline Pressure in, atm & 98.85 & 99.375 & 100.075 & 100.15 & 100.175 \\
\hline $\begin{array}{c}\text { First Quench flow, } \\
\mathrm{KNm} 3 / \mathrm{h} \\
\end{array}$ & 76.25 & 64.75 & 77.275 & 89.975 & 81.25 \\
\hline Flow in, $\mathrm{kNm} 3 / \mathrm{h}$ & 661.575 & 653.275 & 703.6 & 709.375 & 707.725 \\
\hline $\begin{array}{c}\text { Methanol crude, } \\
\text { ton/day }\end{array}$ & 2231.7 & 2046.5 & 2249.7 & 2242 & 2236.7 \\
\hline Operation days & 548 & 608 & 677 & 723 & 828 \\
\hline Temperature in, ${ }^{\circ} \mathrm{C}$ & 232.35 & 233.8 & 236.425 & 236.75 & 240.826 \\
\hline Pressure in, atm & 100.2 & 100.1 & 100.075 & 100.3 & 102.775 \\
\hline $\begin{array}{c}\text { First Quench flow, } \\
\mathrm{KNm} 3 / \mathrm{h}\end{array}$ & 79.7 & 61.8 & 64.75 & 56 & 41.75 \\
\hline Flow in, kNm3/h & 719.45 & 739.1 & 733.3 & 732.7 & 747.125 \\
\hline $\begin{array}{c}\text { Methanol crude, } \\
\text { ton/day }\end{array}$ & 2275.4 & 2297.3 & 2292.5 & 2293.8 & 2353.2 \\
\hline Operation days & 856 & 917 & 978 & 1020 & 1080 \\
\hline Temperature in, ${ }^{\circ} \mathrm{C}$ & 241.125 & 243.75 & 244.725 & 244.85 & 274.075 \\
\hline Pressure in, atm & 102.725 & 103.9 & 104.825 & 104.8 & 104.775 \\
\hline $\begin{array}{c}\text { First Quench flow, } \\
\mathrm{KNm} 3 / \mathrm{h}\end{array}$ & 40.95 & 31.95 & 37.075 & 29.125 & 21.5 \\
\hline $\begin{array}{l}\text { Flow in, } \\
\mathrm{kNm} 3 / \mathrm{h}\end{array}$ & 742.675 & 760.475 & 772.15 & 743.35 & 750.175 \\
\hline $\begin{array}{c}\text { Methanol crude, } \\
\text { ton/day }\end{array}$ & 2344 & 2340.9 & 2350 & 2298.3 & 2342 \\
\hline
\end{tabular}

And, for Methanol synthesis from CO2, was used the model presented by Skrzypek et al. (1991) determined over $\mathrm{CuO} / \mathrm{ZnO} / \mathrm{Al} 2 \mathrm{O} 3$ commercial polish catalyst, with mass relation 60/30/75. The parameters range was specialty wide for reactants concentration, temperature from 473 to $513{ }^{\circ} \mathrm{C}$, pressure from 5 to $7 \mathrm{Mpa}$ and gas initial flowrate of 0.2 mole/min. The Following kinetic expression for methanol production was determined:

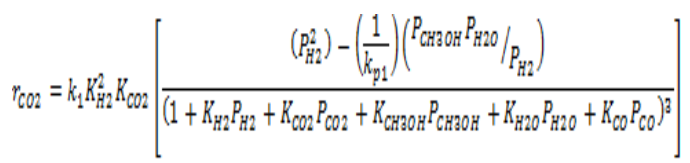

With the following parameters, and the information shown in Table 3:

$$
\begin{aligned}
& k_{1}=3 x 10^{9} E X P\left\lfloor\frac{-25}{R T}\right\rfloor \mathrm{Kg}-\text { mole/kg_cat } \mathrm{h} \\
& K_{\mathrm{i}}=K_{\text {io }} E X P\left[\frac{\Delta H_{\mathrm{i}}}{R T}\right\rfloor \mathrm{atm}^{-1}
\end{aligned}
$$

Table 3- Frequency factors and activation energy

\begin{tabular}{|l|c|c|c|c|c|}
\hline Component & $\mathrm{CH}_{3} \mathrm{OH}$ & $\mathrm{CO}$ & $\mathrm{H}_{2} \mathrm{O}$ & $\mathrm{H}_{2}$ & $\mathrm{CO}_{2}$ \\
\hline $\mathbf{K}_{\mathbf{i o}}$ & $0.11 \times 10^{-9}$ & $5 \times 10^{-9}$ & $3.5 \times 10^{-7}$ & $1.4 \times 10^{-7}$ & $4.4 \times 10^{-7}$ \\
\hline $\begin{array}{l}\Delta \mathbf{H}_{\mathbf{i}}, \\
\mathbf{k c a l} / \mathbf{m o l e}\end{array}$ & 7 & 18 & 18 & 18 & 18 \\
\hline
\end{tabular}

\section{Mathematical model}

For the studied reactor, a one-dimensional pseudohomogeneous basic model was selected, which is a simple model that does not require complex calculation tools for solving differential equations. De Maria, R. et al. (2013) compared the pseudo-homogeneous model with the heterogeneous in methanol synthesis finding that the result obtained for both models do not have significant differences and it validates the model selected for this study.

For the mathematical model selected, the following aspects were supposed:

- There are not temperature and concentration gradients between the fluid and the catalyst. That means, the fluid temperatures and concentration are the same on the catalyst surface.

- The gradients exist only in the axial direction and there is not stirred effect which implies conversion and temperature uniformity.

- The transport mechanism is due to the flow, which is considered ideal (the viscous effects are neglected.).

- The velocity profile is plain in whatever bed transversal section.

Other consideration are taken:

- Adiabatic operation

- Steady-state

- The mass and heat axial dispersion is neglected because the bed length $\mathrm{L}$ is more than 350 particle diameters.

On base in the previous assumption, the reactor model was designed. The continuity equation for both reactants in terms of concentration and the energy equation may be written, for constant density: 


\section{International Journal of Engineering Applied Sciences and Technology, 2019 \\ Vol. 4, Issue 7, ISSN No. 2455-2143, Pages 35-41 \\ Published Online November 2019 in IJEAST (http://www.ijeast.com)}

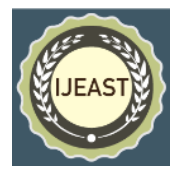

Mass balance for $\mathrm{CO}, \mathrm{CO}_{2}$

$-u_{s} \frac{d C_{A}}{d z}=\rho_{B} \gamma_{A}$

Heat balance

$u_{s} \rho_{g} C_{\mathrm{p}} \frac{d T}{d z}=-(-\Delta H) \rho_{B} r_{A}-4 \frac{U}{d t}\left(T-T_{\gamma}\right)$

Initials boundary conditions: $\mathrm{C}_{\mathrm{A}}=\mathrm{C}_{\mathrm{Ao}}$ at $\mathrm{Z}=0$

$$
\mathrm{T}=\mathrm{T}_{\mathrm{o}} \quad \text { at } \mathrm{Z}=0
$$

\section{Pressure drop}

Leva Equation which is applicable for both laminar and turbulent flow was used for catalytic bed pressure drop calculation:

$\frac{d p t}{d z}+\frac{2 f m G^{2}(1-z)^{1-n}}{d p g \rho_{g} \Psi^{3-n} \varepsilon^{3}}=0$

With initials boundary conditions $\mathrm{p}_{1}=\mathrm{p}_{\mathrm{Ao}}$ at $\mathrm{Z}=0$

\section{E. Effectiveness factor}

Because the main reactions in the methanol synthesis is strongly exothermic, catalytic pills close the isothermal conditions could be considered.

Then the main resistance to the heat transference is in the fluid surrounding the pill and the main resentence inside the pill is the mass transference. When those gradients inside the pill are presented an effectiveness factor is used to fix the intrinsic kinetic $r A$ with the data of the global kinetic $\langle\mathrm{R}\rangle$.

$$
<\boldsymbol{R}>\boldsymbol{\eta} \boldsymbol{r}_{\boldsymbol{A}}
$$

In this study, a theoretical effectiveness factor was determined through the Thiele module:

$\eta_{\mathrm{i}}=\frac{1}{\phi_{\mathrm{i}}} \frac{\left[a \phi_{\mathrm{i}}\right] \operatorname{coth}\left[a \phi_{\mathrm{i}}\right]-1}{a \phi_{\mathrm{i}}}$

The Thiele module is calculated from the following equation for each reaction:

$\phi=\frac{v_{D}}{s_{x}} \frac{\overline{r_{v}\left(c_{s}^{5} y \rho_{s}\right.}}{\sqrt{2}}\left[\int_{C_{s}}^{c_{s}^{s}} D e(c) r_{y}(c) \rho_{g} d c\right]^{-1 / 2}$

\section{A. Activity function}

During the operation time, the catalyst is under several operational conditions, as a consequence of that the catalyst can lose activity along the operational time. For that the life of the catalyst is divided in three-step: SOR (start of run) occurred at the beginning of the operation time when the catalyst show its maximum activity, MOR (middle of run) when the catalyst activity remains stabilized and the EOR (end of run) when the catalyst eventually loss activity until its replacement is required.

An activity function can consider those effects and reduce the deviations between the ideal data from the kinetic model and the operational data. In order to have an empirical activity function depending on the operational time, models similar to presented by Froment, G. and Bischoff, K. (1979) were considered. These models were previously evaluated by Lárez F. (1998) with operational data from a methanol plant, finding that the two models, given in table 3 , shown the best statistics regression.

The activity function was determined by score. For that in the simulation program for each operational day, the kinetic equation for both $\mathrm{CO}$ and $\mathrm{CO} 2$ was multiply by a constant and numerical value close to one $(1.5-0.7)$, the program was ran and the methanol calculated was compared with the actual, if they are similar this value was taken for activity function, if they are different the procedure is repeated with another value.

\section{RESULTS AND DISCUSSION}

Several authors as Panahi, P. et al. (2012), De María, R. et al. (2013), Yusuf, S. et al. (2010) and Grazia, L. (2018) have previously studied the simulation of the methanol synthesis process in shell and tube Lurgi type reactor. In this study, a computer program was written to simulate the Mitsubishi Gas Chemical adiabatic five packed-bed reactor with inter-step cooling. The one-dimensional and pseudo-homogeneous mathematical model was used together to a theoretical effectiveness factor based on Thiele module and an activity function built from operational data.

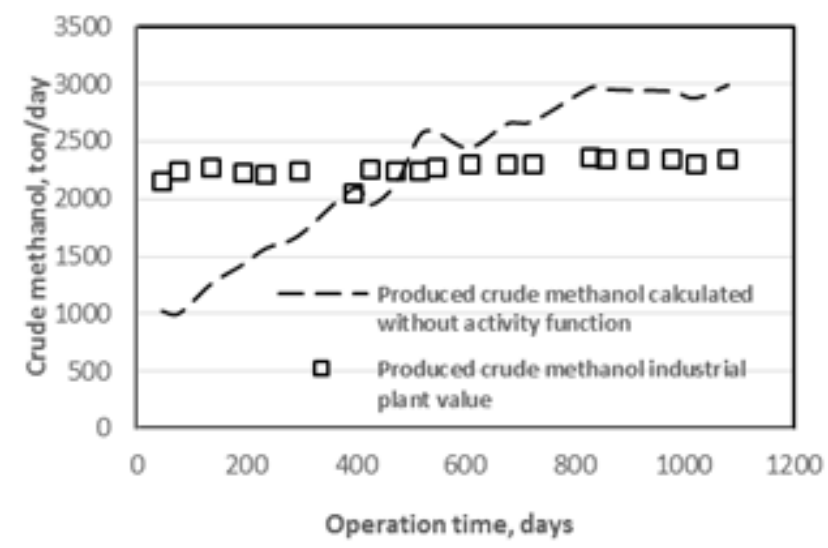

Figure 2. Produced crude methanol values calculated without activity function. Comparison with operational data.

The calculation was performed with a simulator without activity function and the produced crude methanol calculated values were compared with the plant data in Figure 2. There is a difference between values calculated at the start and at the 


\section{International Journal of Engineering Applied Sciences and Technology, 2019 \\ Vol. 4, Issue 7, ISSN No. 2455-2143, Pages 35-41 \\ Published Online November 2019 in IJEAST (http://www.ijeast.com)}

end of the catalyst's life. The variations at the start of catalyst life could be related to the initial activity of the catalyst; due the industrial catalyst shows its maximum catalytic activity during the initial period of life.

In addition, a stable tendency from the methanol production plant data was observed while the calculated data show a slight increase at the end of the operation time. The real data stable behavior is due to the pressure, temperature and flow changes made by the plant operators in order to hold the drop of the methanol conversion produced by the catalysis progressive deactivation (aging). Otherwise, when the simulator model does not consider deactivation, ideal crude methanol production values for the studied conditions were found.

To reduce the differences illustrated in Figure 2, an activity function was built. The activity function values generated by the score are listed in Table 4 . These data were fixed to the equations found in Table 3.

Table 3.Table 4- Estimated values for activity function

\begin{tabular}{|c|c|}
\hline Operation time, days & Activity function \\
\hline 47 & 1.5100 \\
\hline 78 & 1.4470 \\
\hline 137 & 1.3260 \\
\hline 195 & 1.2560 \\
\hline 236 & 1.1660 \\
\hline 296 & 1.1660 \\
\hline 397 & 1.0940 \\
\hline 428 & 1.0540 \\
\hline 474 & 1.0240 \\
\hline 518 & 1.0085 \\
\hline 548 & 0.9750 \\
\hline 608 & 0.9588 \\
\hline 677 & 0.8980 \\
\hline 723 & 0.8871 \\
\hline 828 & 0.8322 \\
\hline 856 & 0.8256 \\
\hline 917 & 0.7750 \\
\hline 978 & 0.7380 \\
\hline 1020 & 0.7382 \\
\hline 1080 & 0.7035 \\
\hline & \\
\hline
\end{tabular}

According to the statistical results of the Table 5, both studied models could represent the data because SSR (sum of the squared residual) values are $>$ than SSE (sum of the square by random errors) and the calculated Fisher $\mathrm{F}$ values are > than 10 times the critic Fisher F values. However, for model 2 the difference between Fisher F calculated and the critic Fisher $\mathrm{F}$ is higher than the model 2 , for that reason the model 2 is selected as the best model that represents the tested data.
Then, the activity function has the following form:

$$
\theta=\frac{1}{(0.6475+0.0006923 t)}
$$

Where: $\mathrm{t}$ is the operational time in days.

Table 5- Variance analysis result for activity models

\begin{tabular}{|c|c|c|c|c|}
\hline Model & SSR & SSE & F calculated & F critic \\
\hline 1 & 0.9528 & 0.0151 & 1139.1500 & $9.9605 \mathrm{E}-18$ \\
\hline 2 & 0.9684 & 0.0072 & 2408.8627 & $1.2641 \mathrm{E}-20$ \\
\hline
\end{tabular}

Table 6- Linear regression results for activity function model 2

\begin{tabular}{|c|c|c|c|c|}
\hline Equation & $\boldsymbol{\beta}$ & $\boldsymbol{\alpha}$ & $\begin{array}{c}\text { Correlation } \\
\text { index }\end{array}$ & $\begin{array}{c}\text { Determination } \\
\text { coefficient }\left(\mathbf{R}^{2}\right)\end{array}$ \\
\hline $\boldsymbol{\Theta}=\mathbf{1} /(\boldsymbol{\beta}+\boldsymbol{\alpha})$ & 0.648 & $6.923 \times 10^{-4}$ & 0.9963 & 0.9926 \\
\hline
\end{tabular}

The comparison between the produced crude methanol actual values versus operation time and the calculated ones with the simulator including the activated function equation 18 is shown in Figure 3. A good representation of the reactor behavior is observed, with absolute deviations calculated for methanol crude produced values less than $8 \%$ and average absolute deviation result of $0.26 \%$.

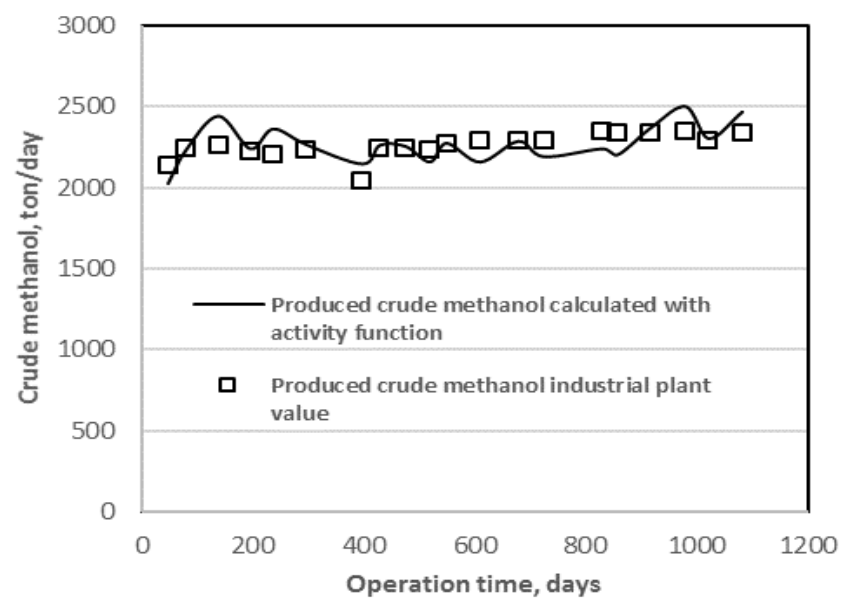

Figure 3. Produced crude methanol calculated with activity function. Comparison with operational data.

Methanol concentration values obtained for each bed at 78 and 1080 operation days are presented in Figure 4. Both curves show a similar tendency being the methanol concentration for 1080 operational days lightly high as it is expected according to the operational conditions. Figure 5, shows the temperature profiles calculated and actual at 87 and 


\section{International Journal of Engineering Applied Sciences and Technology, 2019 \\ Vol. 4, Issue 7, ISSN No. 2455-2143, Pages 35-41 \\ Published Online November 2019 in IJEAST (http://www.ijeast.com)}

1080 operation days. The agreement for the calculated and the operational data is excellent for the first three beds, while for the last two bed the calculated values are higher than the operational data. This behavior could be confirmed that the produced methanol on this industrial reactor comes from $\mathrm{CO}$ and not from the $\mathrm{CO} 2$ as was considered in this study. Skrzypek et al. (1995) suggested that the two reactions which happen in a catalyst base on $\mathrm{Cu}$ are: the water-shift reaction and the reaction to methanol from $\mathrm{CO} 2-\mathrm{H} 2$. These reactions generate a minor temperature profile due to the water-shift reaction is endothermic and the $\mathrm{CO} 2-\mathrm{H} 2$ reaction is less exothermic than the $\mathrm{CO}$ reaction.

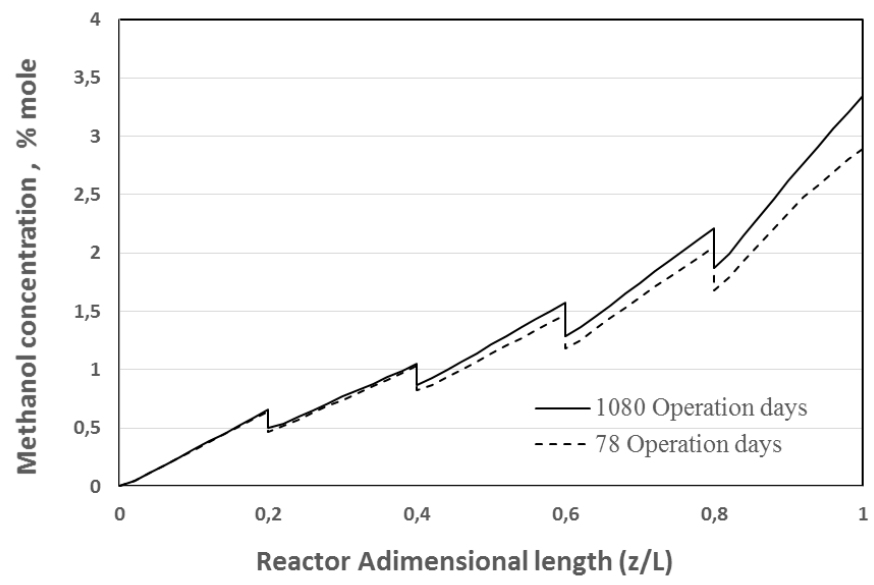

Figure 4. Methanol concentration calculated profile.

The results obtained, with the one-dimensional and pseudo-homogeneous model using a theoretical model for effectiveness factor based on Thiele module and an empirical activity function model from operational data, coincide enough to conclude that the sophisticated models are not required, because the contribution is not decisive in the reactor behavior.

\section{CONCLUSION}

In this study, a simulation of industrial Mitsubishi methanol synthesis reactor has been carried out

The stationary one-dimensional pseudo-homogeneous model, with activity function proposed in this study, adjusts the behavior of the industrial reactor, with absolute deviations for crude methanol production values less than $8 \%$ and average relative deviation of $0.26 \%$.

The activity factor proposed, to take into account the maximum activity at the beginning and the deactivation at the end of the life of the catalyst is an operational time-dependent function that fixes calculated data with a correlation index $\mathrm{R}$

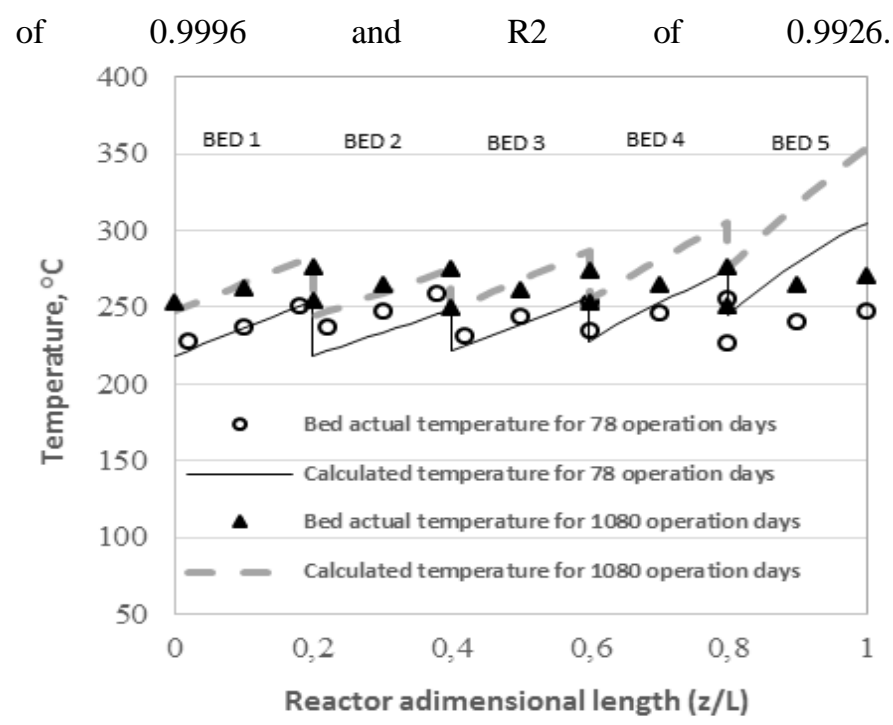

Figure 5. Temperature calculated values. Comparison with operational data.

This one-dimensional and pseudo-homogeneous model proposed has an accurate that lets considered valid for the design and simulation of the catalytic adiabatic and multi-bed reactor of methanol synthesis at low pressure. Sophisticated models are not required, because the contribution is not decisive in the reactor behavior.

\section{ACKNOWLEDGMENT}

The authors grateful to F. Lárez for the support with the operational data and information from METOR plant provided in his work.

\section{REFERENCE}

1. Bos. A.; Borman, P.; Kuczynski, M. and Westerterp, K. (1989). The Kinetics of the Methanol Synthesis on a Copper Catalyst: An Experimental Study. Chemical Engineering Science, Vol.44, No11, (pp. 2435-2449).

2. De María, R.; Díaz, I.; Rodríguez, M. and Sáiz, A. (2013). Industrial Methanol from Syngas: Kinetic study and process simulation. International Journal of Chemical Reactor Engineering. 11(1), (pp. 469-477).

3. Froment, G. and Bischoff, K. (1979). Chemical Reactor Analysis and Design. John Wiley \& Sons, Inc. EEUU, (p. 290).

4. Grazia, L. (2018). Methanol Synthesis: Optimal solution for a better Efficiency of the process. Processes, Vo. 6, (pp. 1-20).

5. Lárez, F. (1998).Formulación de Una Nueva Estrategia para el Manejo del Catalizador Empleado en el Reactor de Síntesis de Metanol de la Planta METOR, S.A. Tesis de Grado, Universidad de Oriente, Venezuela. 


\section{International Journal of Engineering Applied Sciences and Technology, 2019 \\ Vol. 4, Issue 7, ISSN No. 2455-2143, Pages 35-41 \\ Published Online November 2019 in IJEAST (http://www.ijeast.com)}

6. Løvik I. (2001). Modelling, estimation and optimization of the methanol synthesis with catalyst deactivation. Doctoral thesis, Norwegian University of Science and Technology, (p. 127).

7. Panahi, P.; Mousavi, S.M; Niaei, A.; Farzi, A. and Salari, D. (2012) Simulation of the methanol synthesis from synthesis gas in fixed bed catalytic reactor using mathematical model and neural networks. International Journal of Scientific and Engineering Research, Vol. 3, No 2, (pp. 1-7).

8. Rezaie, N.; Jahanmiri, A.; Moghtaderi, B.; Rahimpour, M.R. (2004). A Comparison of Homogeneous and Heterogeneous Dynamic Model for Industrial Methanol Reactors in the Present of Catalyst Deactivation, Chemical Engineering and Processing 44, (pp 911-921).

9. Skrzypek, J.; Lachowska, M. and Moroz, H. (1991) Kinetics of the Methanol Synthesis over commercial Copper-Zinc Oxide Alumina Catalyst Chemical Engineering Science, Vol.46, No11, (pp. 2809-2813).
10. Skrzypek, J.; Lachowska, M.; Grzesik, M.; Sloczynski, J. and Norwak, P. (1995). Thermodynamics and Kinetics of the Low-Pressure Methanol Synthesis. The Chemical Engineering Journal 58, (pp. 101-108).

11. Thermodynamics and Kinetics of the Low-Pressure Methanol Synthesis. The Chemical Engineering Journal 58, (pp. 101-108).

12. Tijm P.J.A., Waller F.J. and Browne D.M. (2001). Methanol technology developments for the new millennium. Applied Catalysis A: General, vol. 221, (pp. 275-282).

13. Yusuf, S.; Anh Np, Zabiri, H. (2010) Simulation Study of an Industrial Methanol Reactor Based on a simplified Steady-state model. IJRRAS; Vol. 5, (pp. 213-222).

14. Zhang Y., Yang R. and Tsubaki N. (2008) A new lowtemperature methanol synthesis method: Mechanistic and kinetics study of catalytic process. Catalysis Today, vol. 132, (pp. 93-100). 